\title{
А.Л. Синища
}

\section{ПЕРВОЕ (СТАРОЕ) СТАТИСТИЧЕСКОЕ ОБОЗРЕНИЕ ШОТЛАНДИИ КАК ИСТОЧНИК ДЕМОГРАФИЧЕСКИХ ДАННЫХ О НАСЕЛЕНИИ ШОТЛАНДИИ КОНЦА ХVIII В.}

\author{
Рассматривается население Шотландии конца XVIII в., а также то, какие демографические сведения можно получить из \\ первого статистического обозрения Шотландии, проведенного под руководством Дж. Синклера в 1790-1799 гг. Делается \\ вывод, что обозрение позволяет определить общую численность населения страны, его распределение по полу и возрасту и \\ средний размер семьи, хотя и неточно. Для оценки рождаемости, брачности и смертности надо привлекать приходские ре- \\ гистры и другие источники данных. \\ Ключевые слова: население Шотландии; первое (старое) статистическое обозрение Шотландии; Джон Синклер; история \\ статистики; историческая демография.
}

Изучение населения в настоящее время характеризуется необходимостью рассматривать большие объемы информации за длительный временной период. Это повышает качество исследований и раздвигает их временные рамки. Для облегчения доступа к таким массивам информации в последние годы были созданы базы демографических данных. Наиболее известными из них являются Integrated Public Use Microdata Series (https://www.ipums.org/), Human Fertility Database (http://www.humanfertility.org/cgi-bin/main.php), Human Mortality Database (http://www.mortality.org/). Такие базы есть и для отдельных стран, поскольку они очень важны в работах по исторической демографии (напримep, Scottish Economic History Database, 1550-1780 (http://www.iisg.nl/hpw/scotland/). Однако в настоящее время в электронный формат переведено не все. Ряд источников, который активно используется и который представляет собой достаточно полный срез жизни населения за некоторый период времени, продолжает существовать в изначальном формате (максимум, что сделано, - их сканирование). Они дают массу информации, которую не всегда можно представить в цифровом формате. Наиболее известными представителями таких источников являются статистические обозрения, в которых много описательных элементов.

В России подобное обозрение было подготовлено и опубликовано в XIX в. (1837-1854 гг.). Однако наиболее глубокое распространение этот жанр получил в Шотландии, где было издано три статистических обозрения, которые охватывали территорию всей страны и множество более мелких, затрагивающих одно или несколько графств. Первое (старое) статистическое обозрение было проведено и опубликовано в 1790-1799 гг. еще до проведения первой переписи населения. Второе (новое) статистическое обозрение было проведено в середине XIX в. (18341845 гг.), когда переписи стали регулярными, но текущий учет продолжал находиться в ведении Церкви. Третье статистическое обозрение было проведено в ХХ в. и растянулось во времени с 1947 по 1992 г.

Распространенность статистических обозрений именно в Шотландии неудивительна. В этой стране сильны генеалогические исследования, что стимулирует развитие изучения населения, помноженные на стремление к путешествиям. Еще до XVIII в. шотландцы были известны как путешественники и купцы, например, в XVII в. в Новую Шотландию переехало около 200 тыс. шотландцев, а в Речь Посполитую в начале того века - 30-40 тыс. человек [1]. В значительной степени это было связано с нехваткой пахатной земли [2. Р. 174] при высокой рождаемости. Все это помогло получить исследования, которые без преувеличения можно назвать энциклопедией жизни населения Шотландии. Правда, как показывает российская и шотландская практика проведения подобных обследований, материалы для них собираются очень долго, что снижает их ценность по ряду вопросов, например, по демографии, поскольку данные устаревают и становятся несопоставимыми.

Для исследования была выбрана Шотландия в силу нескольких причин. Во-первых, по Шотландии доступны сведения за период и до проведения первой официальной переписи населения. Во-вторых, населению Шотландии свойственна значительная миграционная подвижность, что сильно влияет на его численность и состав, особенно в Горной Шотландии и на островах. В-третьих, социальные катаклизмы XVIII в. сильно повлияли на страну и ее дальнейшее развитие. В-четвертых, в Шотландии активно ставился вопрос об изучении населения еще до проведения официальных государственных переписей населения, то есть частная инициатива в этом вопросе была широко распространена и находила поддержку.

Для рассмотрения было выбрано первое статистическое обозрение, поскольку оно является первой успешной попыткой проведения полного статистического описания страны целиком, на методологию которого опирались при проведении последующих статистических описаний, и важной вехой в статистике Шотландии. Кроме того, в нем большое внимание было уделено демографическому развитию страны и некоторые показатели рассмотрены не только за XVIII в., но и за XVII в.

\section{История вопроса и предшественники Дж. Синклера}

В отечественной литературе население Шотландии изучено слабо. Мы смогли найти лишь несколько работ [3-8], да и то, про статистическое обозрение говорится лишь в одной [9], что повышает значимость данной статьи.

За рубежом публикаций гораздо больше, поскольку почти все работы, посвященные истории Шотлан- 
дии или ее экономике, а также истории Великобритании, обязательно имеют главу, в которой рассматривается динамика численности населения Шотландии и ее влияние на социальные и экономические процессы. В связи с этим мы можем особо выделить лишь несколько работ, которые посвящены именно демографической истории Шотландии [10-18]. Существуют и отдельные статьи, посвященные истории населения, но их достаточно много, чтобы выделять особо какието их них.

Р. Плэкетт выделял два явления, которые повлияли на проведение столь масштабной работы: идеологию улучшения и «перепись» населения Шотландии, которая была проведена в 1755 г. [19. Р. 247]. Если с первым не согласиться нельзя, поскольку вопрос об сельскохозяйственных улучшениях был одним из пунктов рассылаемой священникам анкеты, то второе более сомнительно, поскольку в XVIII в. статистика стала активно проникать в жизнь общества ${ }^{1}$ и обследований населения (или проектов подобных исследований) было проведено достаточно много помимо «переписи» А. Уэбстера. В той или иной степени описание Шотландии (включая естественнонаучное и данные о численности населения) представлено в работах М. Мартина [21-22], Д. Монро [23], Т. Пеннанта [24-25], Дж. Босуэлла [26], С. Джонсона [27], Дж Уокера [7, 28-30] и др. Попытки описать Шотландию и ее население со стороны Церкви проводились в 1620-1630-е, 1720-1744 (географическое описание), 1743-1744 и 1755 гг. (описание населения), но все они за исключением проекта А. Уэбстера не были реализованы. Тем не менее значение мероприятий по сбору данных, проведенных под руководством А. Уэбстера, для шотландской статистики велико, хотя бы в силу того, что он показал возможность сбора сведений о населении по почте на основе ответов только приходских священников. Более подробно о целях Уэбстера и его работе см. [12, 31-32].

Можно привести и третью причину, о которой Плэкетт мало говорит. Обследование пришлось на период Шотландского Просвещения - времени, которое подарило Шотландии и миру множество замечательных идей и людей. В стране отмечался интеллектуальный подъем, поэтому неудивительно, что количество попыток описать страну и определить численность ее населения в масштабах всей страны перешло на качественно новый уровень.

Вопрос численности населения был актуален, учитывая все те социальные и экономические трансформации, которые в XVII-XVIII вв. прошла Шотландия. Однако оценки численности населения страны в целом привели не только А. Уэбстер и Дж. Синклер 2. Этот вопрос интересовал и других исследователей [32. Р. 199; 37. Р. 384-385]. Тем не менее именно Дж. Синклер смог заручиться поддержкой властей и провести оценку численности населения Шотландии в начале промышленной революции (проект параллельного проведения аналогичного обследования и в Англии был отклонен Церковью Англии). Несмотря на то, что Дж. Синклер опирался на труды своих представленных выше предшественников, включая Дж. Стюарта, который отмечал, что политика, направленная на увеличение численности населения, невозможна без точного подсчета числа жителей страны, приход за приходом [38. Р. 73], вклад самого Синклера в проведение и успех мероприятия является решающим.

Про самого Джона Синклера существуют отдельные работы (напр., см. [39]), тогда как работы, посвященной его главному труду, нет. Его работа высоко оценивается статистиками и историками статистики [40-43], однако требует более пристального внимания. В данной работе мы познакомим отечественного читателя с этим интересным трудом и рассмотрим, какие сведения демографического характера из него могут быть использованы в современных условиях.

\section{Статистическое обозрение Шотландии как источник данных о населении Шотландии}

Основной единицей обследования был приход, но не все священники понимали, что от них требуется, поэтому была разработана и разослана специальная анкета [44. Р. viii-x]. Это было безусловным успехом Дж. Синклера, поскольку она обеспечила унификацию получаемых ответов и заложила основу для проведения последующих статистических обозрений. В нее вошли 166 вопросов [33. Appendix A, P. XX-xxxiv], которые были разделены на четыре части.

В первую часть (вопросы с 1 по 40) попали вопросы, посвященные географии и естествознанию. Они касались истории названия прихода, его расположения, особенностей почвы, погоды, наличия минералов, рек, озер, гор, пещер, флоры, фауны и прочих аналогичных особенностей прихода.

Вторая группа вопросов была посвящена населению. Она была самой большой (вопросы с 41 по 100), поскольку численности населения уделялось самое пристальное внимание - в оглавлении каждого тома, начиная со второго, из всех возможных сведений о приходах приводится только динамика численности населения. Синклера интересовали следующие данные: его численность, состав по полу, численности проживающих в городах, деревнях и сельской местности (не во всех приходах были населенные пункты [45. Р. 248, 250]), среднегодовое число рождений, браков и смертей, возрастное распределение (до 10 лет, от 10 до 20 лет, от 20 до 50 лет, от 50 до 70 лет, от 70 до 100 лет, старше 100 лет), причины долгожительства, профессиональный состав населения, этнический состав (в отдельные группы выделялись евреи, цыгане, негры, иностранцы, приехавшие из других частей Соединенного королевства, приехавшие из других приходов Шотландии) и причины эмиграции и иммиграции, религиозный состав, число рождений в браках, причины смертей и распространенные заболевания, брачная и семейная структуры населения, причины депопуляции (если наблюдалась), число заселенных и незаселенных домов и среднее число проживающих под одной крышей.

Третья группа вопросов (вопросы со 101 по 116) касалась производства. Задавались вопросы о площади прихода, какие растения и животные выращиваются и собираются, как распределена площадь по видам 
деятельности, обеспечивает ли приход себя продовольствием, что импортируется, что экспортируется, какие есть полезные ископаемые.

В рамках четвертой группы (вопросы со 117 по 160) задавались различные вопросы о языке, ренте, священниках и их жизни, бедных и видах помощи для них, ценах на широкий перечень товаров в прошлом и настоящем, видах используемого топлива, заработной плате для различных профессий, росте жителей, значимых событиях в истории этой местности, известных местах и людях, имевших отношение к приходу, уровне жизни населения и путях его повышения, числе различных видов повозок и судов.

Наконец, была отдельная, добавленная после, группа из шести вопросов. Они касались состояния дорог, земельной ренты, ограждений в приходах и отношения населения к этому, событиях в 1782 1783 гг., что, вероятно, связано с сильными эпидемиями лихорадки в эти годы, и обычаев и интересных фактов за последние 50 лет.

Мы видим, что программа исследований была обширной, но реализовать удалось далеко не все. К этому имелся ряд причин, значительная часть из которых связана с неполнотой сбора данных.

Во-первых, приходские священники не всегда могли точно сказать число жителей. В ряде приходов численность населения определена приблизительно: около 3 тыс. человек [44. Р. 6], около 1 тыс. человек [44. Р. 66, 74], 1,4-1,5 тыс. человек [44. Р. 98; 46. Р. 32].

При этом во многих приходах были собраны сведения не только об общем числе жителей, но и о его распределении и некоторых тенденциях [44. Р. 22-24, 45-46, 52, 141-144]. В ряде приходов информация дается за длительный период. Например, в приходе Эйр (Ауг) приводятся сведения о числе рождений в разрезе пола за ряд лет, начиная с 1664 г., а по числу смертей в разрезе по полу и возрасту (взрослыйребенок) с 1743 г. [44. Р. 89]. Для некоторых приходов были получены очень важные сведения. Так, священник из прихода Трэнент (Tranent) не только привел подробные сведения о населении прихода [47. Р. 90 95], но составил две интересные таблицы. В первой [47. Р. 92] он представил число смертей с 1755 по 1784 г. по полу по пятилетним возрастным группам, отдельно выделяя детей в возрасте до 5 лет и стариков в возрасте старше 90 лет. Во второй таблице [47. Р. 93-94] он привел данные, которые позволяют рассчитать для мужчин и женщин вероятность умереть для однолетних возрастных групп. Доступная выборка была небольшой (за 1755-1783 гг. численность населения возросла с 2459 до 2496 человек, а к 1791 г. - до 2732 человек, поэтому данные в таблице приведены обобщенно за 30 лет. Это сгладило общие колебания и дает представления о тенденциях в сфере смертности за указанный период.

Во-вторых, священники в Шотландии были привилегированным классом с наиболее высокой средней по стране заработной платой, но уровень их знаний и характер различались. В результате у них была разная степень заинтересованности в участии в обследовании и разная степень подробности ответов. Также приходы различались и по уровню подробности и аккуратности ведения регистров крещений (иногда указывалась дата рождений), заключений браков (или оглашений) и погребений (более подробно о проблемах ведения соответствующих регистров в Шотландии см. [9. Р. 170-171; 44. Р. 201; 48. Р. 556; 49. Р. 292; 50. P. 428; 51. Р. 558; 52. Р. 119-120; 53. Р.-480; 54. Р. 569-570]). Священник мог и не знать о каких-то событиях в жизни прихода, пока ему не сообщали об этом местные жители. Климатические и физические условия в приходах различались, поэтому далеко не все священники могли или хотели уточнять необходимые сведения. Например, в приходе Мейкерстон (Makerston) священник смог с трудом найти лишь четверть от предполагаемого населения (около 250 человек из примерно 1000) [48. Р. 263].

B-третьих, даже в конце XVIII шотландское общество было неоднородным. Можно выделить две основных линии конфликтов, в основном имеющих географическую привязку: англоязычные протестанты Равнинной Шотландии противостояли преимущественно гэлоязычным католикам, проживающим в Горной Шотландии и на островах. Эти противоречия возникли задолго до XVIII в., но неудачные восстания 1715 и 1745 гг. и резкая реакция властей на них, а также массовые огораживания обострили их. Также существовала сильная вражда между отдельными кланами, например, Кэмбеллами и их сторонниками и Макдональдами и их сторонниками, хотя в значительном мере они укладывались в описанные выше противоречия. В результате англоязычные протестантские священники, не знавшие гэльского языка, могли оказаться оторванными от жителей северных приходов Шотландии и не имели информацию в необходимом для ответов на вопросы объеме.

Наконец, ответы на разосланные анкеты даже внутри графств приходили и публиковались крайне неравномерно. В условиях промышленной революции и высокой рождаемости даже за небольшое время в стране происходили значительные изменения, поэтому собираемые сведения быстро устаревали. В результате сложно обеспечить сопоставимость данных даже внутри графств. В связи с этим по приходам информация считается на год сбора сведений, а по стране в целом имеются лишь оценки по состоянию на 1790-1798 гг.

Все это свидетельствует о большой пестроте ответов, о чем говорят и зарубежные исследователи (напр., см. [55. Р. 40]), и снижает ценность статистического обозрения как источника данных. Однако собранные сведения являются уникальными и дают представление о тенденциях демографического развития Шотландии в XVIII в.

\section{Численность населения Шотландии и его характеристики по данным статистического обозрения}

Численность населения в приходе и ее сравнение с данными А. Уэбстера - единственная информация, которая есть для всех приходов. За период с 1755 г. население Шотландии выросло на 261112 человек (табл. 1), что составляет прирост около $0,5 \%$ в год. 
Эти цифры являются примерными, поскольку точные данные были доступны не для всех приходов как в 1790-1798 гг., так и в 1755 г. и являются оценками приходских священников. Численность населения выросла больше в южных графствах. Это можно связать с ростом городов, которых было больше в южных графствах, а также с тем, что эмиграция из страны в них была меньше.

Численность населения Шотландии в 1755 и 1790-1798 гг.

\begin{tabular}{|c|c|c|c|c|c|c|c|}
\hline Графство & $\begin{array}{c}\text { Население } \\
\text { в } 1755 \text { г. }\end{array}$ & $\begin{array}{c}\text { Население } \\
\text { в 1790-1798 гг. }\end{array}$ & $\begin{array}{c}\text { Прирост или } \\
\text { убыль, \% }\end{array}$ & Графство & $\begin{array}{c}\text { Население } \\
\text { в } 1755 \text { г. }\end{array}$ & $\begin{array}{c}\text { Население } \\
\text { в 1790-1798 гг. }\end{array}$ & $\begin{array}{c}\text { Прирост или } \\
\text { убыль, \% }\end{array}$ \\
\hline Абердин $^{3}$ & 116836 & 122921 & 5,2 & $\begin{array}{c}\text { Оркнеи и Шетланд- } \\
\text { ские острова }\end{array}$ & 38591 & 43239 & 12,0 \\
\hline Аргайл & 63291 & 76101 & 20,2 & Пиблс & 8908 & 8107 & $-9,0$ \\
\hline Банф & 36521 & 38487 & 5,4 & Перт & 118903 & 133274 & 12,1 \\
\hline Берик & 24946 & 30875 & 23,8 & Ренфрю & 26645 & 62853 & 135,9 \\
\hline Бьют и Арран & 6866 & 10563 & 53,8 & Роксбург & 31273 & 32020 & 2,4 \\
\hline Дамфрис & 41913 & 52329 & 24,9 & Pocc & 42493 & 50146 & 18,0 \\
\hline Данбартон & 13857 & 18408 & 32,8 & Сазерленд ${ }^{4}$ & 20774 & 22961 & 10,5 \\
\hline Инвернесс & 64656 & 73979 & 14,4 & Селкирк & 4368 & 4314 & $-1,2$ \\
\hline Кейтнесс & 22215 & 24802 & 11,6 & Стерлинг & 38813 & 46663 & 20,2 \\
\hline Керкубри & 21205 & 26959 & 27,1 & Уигтон & 16466 & 20983 & 27,4 \\
\hline Кинкардин & 24346 & 26799 & 10,1 & Файф & 81570 & 87250 & 7,0 \\
\hline Кинросс & 4889 & 5302 & 8,4 & Форфар & 68297 & 91001 & 33,2 \\
\hline Клэкманнан & 9003 & 8749 & $-2,8$ & Хаддингтон & 29709 & 28966 & $-2,5$ \\
\hline Кромарти & 5163 & 5284 & 2,3 & Эдинбург & 90412 & 122655 & 35,7 \\
\hline Ланарк & 81726 & 125254 & 53,3 & Эйр & 59268 & 75544 & 27,5 \\
\hline Линлитгоу & 16829 & 17570 & 4,4 & Элгин & 28934 & 26080 & $-9,9$ \\
\hline Нэрн & 5694 & 6054 & 6,3 & Итого & 1265380 & 1526492 & 20,6 \\
\hline
\end{tabular}

Во второй половине XVIII в. прирост населения в Шотландии обеспечивала рождаемость, поскольку миграционное сальдо было отрицательным, но внутри страны влияние оказывали и другие причины. В некоторых отчетах священники привели не только численность населения, но и указали причины, которые повлияли на ее динамику [44. Р. 6, 123, 173-174; 45. P. 210; 46. P. 237-238, 254-256, 569-570; 48. P. 182, 333-334; 49. P. 133 , 397; 53. P. 220; 54. P. 548-549; 56. P. 219, 236, 410; 57. Р. 610; 58. Р. 159; 59. Р. 261]. Мы привели лишь часть примеров.

Можно выделить шесть причин, которые снижали численность населения. Население прихода уменьшалось из-за укрупнения ферм, что требовало меньше людей для ведения сельского хозяйства. Следует отметить, что возврат к практике предоставления небольших наделов стал наблюдаться лишь незадолго до обследования Синклера. Использование более прогрессивных методов обработки земли снизило потребность в арендаторах, но увеличило стоимость земли и потенциальную ренту. Многие собственники земли стали сами обрабатывать землю, не привлекая для этого арендаторов, что снизило численность населения в таких приходах. Смена специализации с сельского хозяйства на животноводство тоже снижало потребность в людях, так как в новых условиях одному человеку было надо столько же земли, сколько ранее 10-14. Наличие рядом крупных городов стимулировало переселение, поскольку в них проще найти работу. Наконец, население сокращалось, когда собственники не жили на земле и за ней не надо ухаживать.

Население увеличивалось в следующих случаях. Удачное расположение прихода и наличие дорог положительно влияло на число его жителей. Использование удобрений на основе извести и ввод в сельскохозяйственный оборот новых земель тоже увеличива- ло численность населения. Это делало сельское хозяйство снова привлекательным по сравнению с животноводством. Также положительно на численность населения влияла более активная ловля сельди. Увеличивало население и развитие производства (мануфактур) в приходе, поскольку там могли работать и дети (пример данных о числе детей см. в [46. Р. 154, 216; 54. Р. 37; 60. Р. 308]), а наличие работы давало уверенность в будущем. Тем не менее развитие мануфактур могло быть и ответом на увеличение численности населения, которое необходимо было занять. Сохранение сельскохозяйственной специализации также препятствовало оттоку населения. Наконец, введение более прогрессивных методов в лечении детей и матерей после родов, а также широкое распространение практики вакцинации (особенно от оспы) способствовало снижению смертности.

Мы видим, что на изменение числа жителей прихода влияли в основном экономические причины. Прогресс в области медицины был менее заметным фактором. Такой аспект, как миграция англоязычного населения вследствие дискриминации по языковому, религиозному и политическому принципам, в отчетах отражен не был, но известно, что эти факторы вносили заметный вклад.

Городов с населением свыше 309 человек в Шотландии было 240 (из них в 119 было более 1000 жителей, а в 7 - более 10000 жителей) [37. Р. 474-478]. В них проживало 545725 человек $(35,8 \%$ от всего населения страны). Правда, сам Синклер отмечал, что по некоторым крупным городам сведения не были получены. В связи с этим он предлагал к указанному числу добавить еще 100000 жителей [37. Р. 478]. В таком случае в городах проживало $42,3 \%$ от всего населения страны. Выбранная Дж. Синклером граница является очень низкой, поскольку в тот период 
существовали деревни с большим числом жителей [44. Р. 453]. Если мы рассмотрим города с численностью населения более 1000 человек, то число их жителей на момент проведения обследования составляло 477373 человека $(31,2 \%$ от всего населения или $37,8 \%$ при добавлении дополнительных жителей).

Данные о половой структуре населения доступны не по всем приходам, поскольку многие священники не предоставили соответствующую информацию. В некоторых случаях священники не приводили распределение по полу, но отмечали, что женщин или мужчин больше (или равное число), и иногда указывали, на сколько больше [50. Р. 300; 51. Р. 98; 52. Р. 175; 54.
Р. 108; 56. Р. 99]. В отношении распределения по полу Синклер смог получить полные или частичные данные об около 410 приходах (около 690 тыс. человек).

Половая структура населения была сильно деформированной: на 100 женщин приходилось лишь 90 мужчин (табл. 2). Равные доли мужчин и женщин были только в Пиблсшайре. Помимо смертности на распределение полов влиял значительный отток из страны молодых мужчин. Географические особенности половой структуры населения выделить нельзя, поскольку среди регионов как с высоким, так и с низким числом мужчин присутствуют представители разных макрорегионов.

Число мужчин на 100 женщин в Шотландии в 1790-1798 гг. 5

Т а бл и ц а 2

\begin{tabular}{|c|c|c|c|c|c|}
\hline Графство & & Графство & & Графство & Росс \\
\hline Абердин & 90 & Кинросс & 87 & 83 \\
\hline Аргайл & 97 & Клэкманнан & 88 & Сазерленд & 89 \\
\hline Банф & 91 & Кромарти & 93 & Селкирк & 89 \\
\hline Берик & 92 & Ланарк & 87 & Стерлинг & 94 \\
\hline Бьют и Арран & $\ldots$ & Линлитгоу & 84 & Уигтон & 96 \\
\hline Дамфрис & 91 & Нэрн & $\ldots$ & Файф & 92 \\
\hline Данбартон & 98 & Оркнеи и Шетландские острова & 82 & Форфар & 94 \\
\hline Инвернесс & 92 & Пиблс & 100 & Хаддингтон & 86 \\
\hline Кейтнесс & 89 & Перт & 92 & Эдинбург & 84 \\
\hline Керкубри & 94 & Ренфрю & 94 & Эйр & 93 \\
\hline Кинкардин & 97 & Роксбург & 88 & Элгин & 87 \\
\hline Шотландия & 90 & & & & \\
\hline
\end{tabular}

Источник: расчеты автора на основе [33, 37, 44-54, 56-63].

Примечание. Здесь и далеев таблицах ... - данных по графству нет или доступны сведения только по одному приходу.

Возрастная структура населения Шотландии в 1790-1798 гг.

\begin{tabular}{|c|c|c|c|c|c|c|c|c|c|}
\hline \multirow{2}{*}{ Графство } & \multicolumn{4}{|c|}{ Возраст } & \multirow{2}{*}{ Графство } & \multicolumn{4}{|c|}{ Возраст } \\
\hline & $<20$ & $20-50$ & $50-70$ & $>70$ & & $<20$ & $20-50$ & $50-70$ & $>70$ \\
\hline Абердин & 38,1 & 39,7 & 17,2 & 5,0 & $\begin{array}{c}\text { Оркнеи и Шетландские } \\
\text { острова }\end{array}$ & 46,4 & 35,6 & 15,0 & 3,0 \\
\hline Аргайл & 48,1 & 35,6 & 12,7 & 3,5 & Пиблс & 45,0 & 37,3 & 14,4 & 3,3 \\
\hline Банф & 39,8 & 37,4 & 16,2 & 6,6 & Перт & 42,4 & 42,0 & 13,1 & 2,5 \\
\hline Берик & 47,5 & 37,3 & 11,6 & 3,5 & Ренфрю & 47,1 & 39,5 & 10,9 & 2,4 \\
\hline Бьют и Арран & $\ldots$ & $\ldots$ & $\ldots$ & $\ldots$ & Роксбург & 43,9 & 40,1 & 13,0 & 3,0 \\
\hline Дамфрис & 46,0 & 36,7 & 13,6 & 3,6 & Pocc & 48,0 & 36,4 & 13,3 & 2,3 \\
\hline Данбартон & & & $\ldots$ & $\ldots$ & Сазерленд & $\ldots$ & $\ldots$ & , & $\ldots$ \\
\hline Инвернесс & 50,7 & 36,8 & 10,1 & 2,4 & Селкирк & $\ldots$ & & 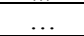 & \\
\hline Кейтнесс & 49,7 & 35,2 & 13,5 & 1,6 & Стерлинг & 44,8 & 38,1 & 14,0 & 3,2 \\
\hline Керкубри & 40,0 & 39,8 & 17,0 & 3,2 & Уигтон & 41,1 & 39,3 & 16,3 & 3,3 \\
\hline Кинкардин & 42,2 & 39,0 & 14,4 & 4,4 & Файф & 44,6 & 40,2 & 12,8 & 2,4 \\
\hline Кинросс & & & 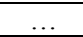 & $\ldots$ & Форфар & 45,6 & 39,6 & 12,3 & 2,5 \\
\hline Клэкманнан & 45,2 & 38,5 & 14,0 & 2,3 & Хаддингтон & $\ldots$ & $\ldots$ & $\ldots$ & $\ldots$ \\
\hline Кромарти & & & $\ldots$ & $\ldots$ & Эдинбург & 42,8 & 41,4 & 13,6 & 2,3 \\
\hline Ланарк & 44,2 & 38,3 & 14,2 & 3,3 & Эйр & 45,6 & 37,6 & 13,9 & 2,9 \\
\hline Линлитгоу & $\ldots$ & $\ldots$ & $\ldots$ & $\ldots$ & Элгин & 44,2 & 35,3 & 14,8 & 5,7 \\
\hline Нэрн & $\ldots$ & $\ldots$ & $\ldots$ & $\ldots$ & Шотландия & 44,4 & 38,6 & 13,7 & 3,3 \\
\hline
\end{tabular}

Источник: расчеты автора на основе [33, 37, 44-54; 56-63]

Джон Синклер хотел знать распределение населения по следующим возрастным группам: 0-20 лет, 20-50 лет, 50-70 лет и старше 70 лет. Это соответствует четырем группам: дети [57. Р. 440], взрослые, пожилые и старики, долгожители. Однако полностью или частично собрать сведения о населении в таком разрезе он смог лишь в около 200 приходах, в отношении около 240 тыс. человек. При этом сведения доступны лишь по небольшим приходам с населением до 5 тыс. человек. В крупных городах священники зачастую не могли предоставить подобную информацию.
Значительное число священников привели распределение населения в приходах в соответствии со своими потребностями и представлением об этом. Подобный подход не позволяет использовать приведенные данные, поскольку они несопоставимы с основной массой отчетов [48. Р. 386; 52. Р. 656; 53. Р. 589; 56. Р. 73, 236, 418; 58. Р. 195; 60. Р. 151, 549; 61. Р. 3839]. Иногда священники приводили информацию по десятилетним возрастным группам и даже в разрезе по полу [44. Р. 510; 51. Р. 401; 52. Р. 586; 59. Р. 312], что на руку исследователям. В одном случае приведе- 
ны сведения по однолетним возрастным группам [50. Р. 619-620].

Исходя из имеющихся данных, дети составляли $44,4 \%$ от всего населения, взрослые - 38,6\%, пожилые и старики - 13,7\%, долгожители - 3,3\% (см. табл. 3). По сравнению с обследованием Уэбстера доля детей возросла на 0,3 процентных пункта, доля взрослых снизилась на 2,6 процентных пункта, а доли стариков и долгожителей выросли соответственно на 1,6 и 0,7 процентных пункта. Можно выделить две тенденции: повышение продолжительности жизни, что выразилось в увеличении доли пожилых, и рост числа детей, что связано, на наш взгляд, со снижением детской смертности из-за вакцинации. Что касается взрослых, то их число сократилось из-за эмиграции в Северную Америку, британские колонии и европейские страны (например, Швецию), где они выступали как наемники, а также поступления на военную службу или торговый флот. Выделить географические закономерности в возрастной структуре населения сложно, поскольку данные доступны лишь по небольшой части населения. Тем не менее в горной части доля детей была в среднем выше, а в равнинной - ниже, тогда как в отношении взрослых и пожилых наблюдалась обратная картина.

Для 31 прихода у нас есть сопоставимое распределение населения и по полу, и по возрасту (из них у
13 - по десятилетним возрастным группам). В них проживало около 38 тыс. человек. Согласно отчетам священников для этого населения мужчин было значительно больше в возрасте меньше 20 лет (105 мужчин на 100 женщин) и немного больше в возрасте и старше 70 лет (102 мужчины на 100 женщин), а женщин значительно больше в возрастах 20-50 лет (83 мужчины на 100 женщин) и 50-70 лет (91 мужчина на 100 женщин).

Данные о среднем размере семьи доступны по примерно 180 приходам (около 400 тыс. человек), а по семи приходам есть полное распределение числа семей с указанием числа членов в каждой. Во многих приходах есть данные о числе занятых домов, но эти понятия могут не совпадать [47. Р. 586; 51. Р. 4; 52. Р. 617; 57. Р. 27, 30, 175-176], поэтому мы учли совсем немного приходов, где священники отметили, что цифры по домам и семьям равны. Средний размер семьи в Шотландии составил 4,6 человека, но в эту цифру попали и семьи, состоящие из одного человека. В статистическом обозрении нет четкой позиции: в некоторых отчетах одиночек называют семьей [61. Р. 308], а в некоторых - нет [44. Р. 453]. Если их не учитывать, то средний размер семьи превысит 5,0 человека. В городах средний размер семьи меньше по сравнению с сельской местностью, а в северных графствах больше чем в южных.

Т а б ли ц а 4

Средний размер семьи в Шотландии в 1790-1798 гг.

\begin{tabular}{|c|c|c|c|c|c|}
\hline Графство & $\begin{array}{c}\text { Средний размер } \\
\text { семьи }\end{array}$ & Графство & $\begin{array}{c}\text { Средний размер } \\
\text { семьи }\end{array}$ & Графство & $\begin{array}{c}\text { Средний размер } \\
\text { семьи }\end{array}$ \\
\hline Абердин & 4,1 & Кинросс & 3,9 & Pocc & 4,8 \\
\hline Аргайл & 5,0 & Клэкманнан & 3,9 & Сазерленд & 5,6 \\
\hline Банф & 4,4 & Кромарти & 4,9 & Селкирк & \\
\hline Берик & 4,5 & Ланарк & 4,6 & Стерлинг & 4,6 \\
\hline Бьют и Арран & $\ldots$ & Линлитгоу & 4,2 & Уигтон & 4,8 \\
\hline Дамфрис & 4,0 & Нэрн & $\ldots$ & Файф & 4,1 \\
\hline Данбартон & $\cdots$ & $\begin{array}{c}\text { Оркнеи и Шетландские } \\
\text { острова }\end{array}$ & 5,3 & Форфар & 4,4 \\
\hline Инвернесс & 5,6 & Пиблс & 4,8 & Хаддингтон & 4,1 \\
\hline Кейтнесс & 5,3 & Перт & 4,5 & Эдинбург & 4,5 \\
\hline Керкубри & 4,6 & Ренфрю & 4,6 & Эйр & 4,7 \\
\hline Кинкардин & $\ldots$ & Роксбург & 4,5 & Элгин & 4,5 \\
\hline Шотландия & 4,6 & & & & \\
\hline
\end{tabular}

Источник: расчеты автора на основе [33, 37, 44-54, 56-63].

Изначально мы хотели рассчитать хотя бы общие коэффициенты рождаемости, брачности и смертности, но из-за нехватки данных были вынуждены отказаться и от этого.

В статистическом обозрении об этих демографических событиях данные приводятся из приходских регистров, а при их использовании существуют проблемы. Во-первых, не везде регистры велись аккуратно и регистрировались далеко не все события, поскольку не все хотели платить регистрационные сборы. Во-вторых, во многих приходах регистрировались не демографические события (рождение, вступление в брак и смерть), а события церковной жизни (крещение, оглашение, отпевание), а это не тождественные события. В отношении рождаемости ситуация осложняется тем, что в Шотландии крестили не младенцев, а детей в возрасте 8-12 лет (в зависимости от прихо- да) и часть из них умирала еще до этого. В отношении регистрации брачности тоже были сложности. Если жених и невеста были из разных приходов, то объявления о предстоящем браке делались в обоих приходах и сведения часто попадали в регистры обоих приходов. В связи с этим регистры дают интересную информацию, но ее использование крайне затруднено и требуются значительные усилия по приведению ее в порядок и вид, подходящий для использования, что выходит за рамки данной статьи.

Имеющиеся данные не позволяют рассмотреть брачную структуру, поскольку сопоставимые данные доступны по очень маленькому числу приходов. В отчетах четко выделяется категория вдовых (иногда с разделением по полу). Зачастую это единственная информация о брачной структуре [50. Р. 82]. Состоящие в браке часто выделяются старше какого-нибудь 
возраста, например 18 [46. Р. 8] или 20 [44. Р. 22] лет, но нет никаких указаний на то, что в более молодом возрасте никто не состоит в браке, ведь в отчетах отмечается, что люди вступали в брак рано. Также нельзя посчитать число состоящих в браке по числу семей, поскольку в приходах в приходе число состоящих в браке мужчин и женщин могло различаться [54. P. 38]. Не состоящие в браке делятся на тех, кто находится в брачном возрасте, но не состоит в браке, и тех, кто ниже определенного возраста, а этот возраст между приходами различается [44. Р. 22; 46. Р. 8; 54. Р. 39]. Несмотря на наличие цифр, иногда связь между числом состоящих в браке и не состоящих в браке установить нельзя [54. Р. 38-39].

Мы отметим лишь некоторые интересные особенности. Во многих приходах священники привели информацию о числе событий за некоторый период времени (от двух до 100 и более лет), иногда с разбивкой по пяти- или десятилетним группам. Подобное представление данных оправданно, так как позволяет сгладить годовые колебания, что актуально в условиях небольшого населения, но не дает информацию о существующих трендах. В некоторых приходах были проведены попытки рассчитать общие коэффициенты, например, в таком виде: «среднее годовое число рождений относится ко всему населению как 1 к 36» [44. Р. 163] (по нашим оценкам рождаемость составляла 30-50\%). На основе данных о части приходов можно сделать вывод о том, что среднее число детей, рожденных в браке, составляло 4-5. В некоторых приходах священники привели сведения о смертности по однолетним [44. Р. 327] или другим, например десятилетним [46. Р. 8; 50. Р. 186], возрастным группам.

Конец XVIII в. в Шотландии характеризовался быстрыми темпами развития экономических отношений. Социальные последствия неудачных восстаний и последовавшей массовой эмиграции не были преодолены, поэтому государству и обществу было необходимо узнать, сколько человек проживает в стране и какими характеристиками они обладают.

В 1755 г. Церковью Шотландии было проведено обследование, которое позволило узнать только численность населения. Однако этого было недостаточно, а результаты обследования не были опубликованы вплоть до середины XX в.

Первое (старое) статистическое обозрение Шотландии, проведенное и опубликованное в последнем десятилетии XVIII в., дало много новых данных о половом и возрастном распределении населения и размере семьи. В нем отмечалось, что численность населения с 1755 г. возросла примерно на 261 тыс. человек. Это является очень хорошим результатом для маленькой страны с высокой эмиграцией. На 100 женщин приходилось всего 90 мужчин, однако в наиболее молодых и наиболее старых возрастах мужчин было больше, что свидетельствует о высокой эмиграции мужчин. Около $41 \%$ населения было моложе 20 лет, а 39\% находились в интервале от 20 до лет. Старше 50 лет было 17\%. Согласно шкале Ж. Божё-Гарнье-Э. Россета можно судить о том, что население находилось на уровне демографической молодости или первого преддверия старости. Средний размер семьи составлял 4,6 человека, однако в их число включались домохозяйства, состоящие из одного человека. Учитывая то, что в браках рождалось в среднем 4-5 ребенка, можно предполагать, что размер семьи, состоящей из двух и более человек, превышал 5 человек.

На динамику численности населения Шотландии оказывали влияние разные факторы. Самым важным являлся экономический. Улучшения в сфере ведения сельского хозяйства как повышали стоимость земли и привлекали дополнительных работников, так и снижали потребность в рабочих руках. Развитие промышленности (особенно табачных и хлопковых мануфактур) уменьшало число занятых в сельском хозяйстве и повышало численность населения в городах. Переход от сельского хозяйства в приходе к животноводству снижало численность населения в нем.

Тем не менее первое статистическое обозрение не лишено и недостатков. Во-первых, статистическое обозрение не является переписью населения в современном понимании этого термина. В нем отсутствовал критический момент - дата, по состоянию на которую проводился опрос, то есть обследование не было одномоментным. Оно не было и всеобщим, так как анкеты рассылались священникам, которые отвечали на вопросы о положении дел в приходе, а не отдельным семьям. Несмотря на наличие единой программы ответы были получены не на все вопросы и из разных приходов было получено разное число ответов. Кроме того, многие священники отвечали на вопросы не так, как требовалось в программе обследования, а так, как могли или хотели. В результате данные между приходами далеко не всегда можно сравнить. Наконец, обследование не было регулярным, что также затрудняет сравнение данных.

Во-вторых, многие данные демографического характера имеют очень примерную оценку. Хотя население в итоговом отчете представлено с точностью до человека, можно утверждать, что погрешность составляет не менее нескольких десятков тысяч человек. Частично это связано с тем, что ответы на анкету собирались на протяжении длительного периода времени и численность населения за это время успела измениться, а частично - с тем, что священники не всегда обладали полной информацией о населении прихода и его характеристиках.

В-третьих, сведения о миграции практически отсутствуют, а сведения о рождаемости, брачности и смертности представлены на низком уровне. Это связано с тем, что во многих приходах регистры велись плохо или совсем не велись, и с тем, что в них учитывались крещения, оглашения и погребения, а не рождения, вступления в брак и смерти. Лишь иногда отмечались именно демографические события. Ответ на эти вопросы требует тщательной работы с приходскими регистрами и другими источниками данных, а не со статистическим обозрением.

Перечисленные недостатки не умаляют заслугу Джона Синклера в том, что статистическое обозрение Шотландии, проведенное под его руководством, позволяет решить главную задачу этого обозрения - дать представление о жизни населения Шотландии на ко- 
нец XVIII в. Эта цель была достигнута, а первое статистическое обозрение Шотландии является важной вехой в изучении населения Шотландии. Можно выделить еще два важных результата проведения и публикации обозрения. Во-первых, была осуществлена некоторая тренировка перед первой государственной переписью населения, проведенной в 1801 г. Вовторых, оно стимулировало дальнейшее развитие социальной мысли и общественную дискуссию о положении дел в стране. Например, Т.Р. Мальтус активно использовал материалы обозрения при работе над своей книгой «Опыт о законе народонаселения» (книга 2, гл. 10). Все сказанное выше позволяет утверждать о том, что первое (старое) статистическое обозрение Шотландии является уникальным источником сведений по населению Шотландии конца XVIII в., который необходимо обязательно использовать, но дополнять данными регистров текущего учета событий, которые вели приходские священники, и другими источниками информации.

\title{
ПРИМЕЧАНИЯ
}

\begin{abstract}
${ }^{1}$ Шотландцы внесли значительный вклад в развитие статистики [20]. Достаточно вспомнить, что шотландцами по происхождению являются такие известные личности, как Р. Гиффен, Дж. У. Юл, П. Бойл и А. Дитон.

${ }^{2}$ Джон Синклер из Ульбстера, 1-й баронет (10.05.1754-21.12.1835) - член Палаты общин от Кейтнесса, пионер пропаганды статистики на английском языке [20. Р. хііi]. Обучался в Университетах Эдинбурга и Глазго, а затем в Тринити-колледже в Оксфорде; был принят в коллегию адвокатов в Шотландии. Член Генеральной Ассамблеи Церкви Шотландии. Основной сферой его научных интересов является сельское хозяйство (более подробно см. [34]) и некоторые близкие вопросы [35]. Также он является автором ряда публикаций по экономике и сельскому хозяйству: History of the Public Revenue of the British Empire (1784), The Code of Health and Longevity (1807), Hints Regarding the Agriculture State of the Netherlands, Compared with that of Great Britain (1815), Сode of Agriculture (1819) и др. Был главой Бюро земледелия (Board of Agriculture and Internal Improvement), созданного в 1793 г. при поддержке премьер-министра Великобритании Уильяма Питтамладшего и просуществовавшего до 1822 г. Инициаторами его создания можно считать Артура Янга (1741-1820), который в конце 1760 начале 1770-х гг. провел выборочное обследование, посвященное сельскохозяйственной экономике [36], и еще с 1769 г. предлагал создание аналогичной организации и Уильяма Маршалла (1745-1818), писателя и исследователя в сфере сельского хозяйства.

${ }^{3}$ Вероятно, в расчетах для этого графства где-то допущена опечатка, поскольку наблюдается расхождение на 20 человек.

${ }^{4}$ Вероятно, в расчетах для этого графства где-то допущена опечатка, поскольку наблюдается расхождение на одного человека.

5 Здесь и далее в таблицах для устранения различий между приходами данные приводятся по графствам. Минимальной границей является наличие в графстве данных хотя бы по двум приходам, хотя, разумеется, это может искажать реальную картину.
\end{abstract}

\section{ЛИТЕРАТУРА}

1. Smout T.C., Landsman N.C., Devine T.M. Scottish Emigration in the Early Modern Period// Europeans on the Move: Studies on European Migration, 1500-1800 / Canny N. (ed.). Oxford : Clarendon Press, 1994. P. 76-112.

2. Dodgshon R.A. Farming Practice in the Western Highlands and Islands before Crofting: A Study in Cultural Inertia or Opportunity Costs? // Rural History. 1992. Vol. 3, № 2. P. 173-189.

3. Звидриньш П.П. Население Великобритании: размещение, состав и воспроизводство. М. : Статистика, 1979.183 с.

4. Ласкова Н.В. «Демографический пресс» как предпосылка шотландской колонизации Америки в XVII веке // Исторические, философские, политические и юридические науки, культурология и искусствоведение // Вопросы теории и практики. 2014. № 6-1 (44). С. 112-115.

5. Ласкова Н.В. Колонизация шотландских окраин в XVI - первой четверти XVII вв. // Вестник Брянского государственного университета. 2016. № 3 (29). C. 43-46.

6. Ласкова Н.В. Несостоявшиеся проекты шотландских колоний в Америке Роберта Гордона из Лохинвара // Известия высших учебных заведений. Северо-Кавказский регион. Серия: Общественные науки. 2011. № 1. С. $70-74$.

7. Королева М.В. Труды Джона Уокера о населении Горной Шотландии и Гебридских островов // Вестник Московского университета. Серия 6: Экономика. 2013. № 2. С. 54-61.

8. Урланис Б.Ц. Рост населения в Европе (опыт исчисления). М. : ОГИЗ-Госполитиздат, 1941. 436 с.

9. Королева М.В., Синица А.Л. Гэльское население Шотландии - от истоков к современности // Этническая демография. М. : МАКС Пресс, 2010. C. $163-191$.

10. Scottish Population History from the Seventeenth Century to the 1930s / M. Flinn (ed.). Cambridge : Cambridge University Press, 1977. P. $x x v+547$.

11. Moody D. Scottish Family History. London : B.T. Batsford, 1988. 219 p.

12. Scottish Population Statistics including Webstrer's Analysis of Population 1755 / Kyd J.G. (ed.). Edinburgh : Scottish History Society, 1952. $107 \mathrm{p}$.

13. Smout T.C. A history of Scottish People, 1560-1830. London : Collins, 1969. 576 p.

14. Devine T.M. The Scottish Nation 1700-2000. London; Allen Lane : The Penguin Press, 1999. xxiii +696 p.

15. Bumsted J.M. The People's Clearance. Highland Emigration to British North America. 1770-1815. Edinburgh : Edinburgh University Press, The University of Manitoba Press, 1982. xvii+305 p.

16. Withers Ch.W.J. Urban Highlanders: Highland-Lowland Migration and Urban Gaelic Culture, 1700-1900. East Linton : Tuckwell Press, 1998. $\mathrm{xvi}+270 \mathrm{p}$.

17. Richards E.A History of the Highland Clearances. Vol. 1: Agrarian Transformation and the Evictions 1746-1886. London : Croom Helm, 1982. $531 \mathrm{p}$.

18. Richards E.A History of the Highland Clearances. Vol. 2: Emigration, Protest, Reasons. London : Croom Helm, 1985. 543 p.

19. Plackett R.L. The Old Statistical Account // Journal of the Royal Statistical Society. Series A (General). 1986. Vol. 149, № 3. P. $247-251$.

20. Pritchard Ch. The Contributions of Four Scots to the Early Development of Statistics // The Mathematical Gazette. 1992. Vol. 76, № 475: The Use of the History of Mathematics in the Teaching of Mathematics. P. 61-68.

21. Martin M. A description of the Western Islands of Scotland: Containing a full account of their situation, extent, soils, product, harbours, bays, tides, anchoring places, and fisheries. The ancient and modern government, religion and customs of the inhabitants, particularly of their druids, heathen temples, monasteries, churches, chappels, antiquities, monuments, forts, caves, and other curiosities of art and nature. Of their admirable and expeditious way of curing most diseases by simples of their own product. A particular account of the second sight, or faculty of forseeing things to come, by way of vision, so common among them. A brief hint of methods to improve trade in that country, both by sea and land. With a new map of the whole, describing the harbours, anchoring places, and dangerous rocks, for the benefit of sailers. To which is added a brief description of the Isles of Orkney, and Schetland. London : Printed for Andrew Bell, at the Cross-Keys and Bible in Cornhill, near Stocks-Market, 1703. $392 \mathrm{p}$. 
22. Martin M. A voyage to St. Kilda, the remotest of the Hebrides or Western Isles of Scotland: giving An Account of the very remarkable Inhabitants of that place, their Beauty and singular Chastity (Fornication and Adultery being unknown among them); their Genius for Poetry, Music, Dancing; their surprising Dexterity in climbing the rocks, and Walls of Houses; Diversion, Habit, Food, Language, Diseases and Methods of Cure; their extensive Charity; their Contempt of Gold and Silver, as below the Dignity of Human Nature; their Religious Ceremonies, Notion of Spirits and Visions, \&c. \&c.. London : D. Browne and L. Davis, 1753. 63 p.

23. Monro D. Description of the Western Isles of Scotland called Hybrides. With the Genealogies of the Chief Clans of the Isles by Sir Donald Monro High Dean of the Isles who travelled through most of them in the year 1549. Glasgow : Thomas D. Morison ; London : Hamilton, Adams \& Co., $1884.68 \mathrm{p}$.

24. Pennant Th. A tour in Scotland and voyage to the Hebrides: MDCCLXXII. Part 1. London : Benjamin White, 1790 . vii+440 pp.

25. Pennant Th. A tour in Scotland and voyage to the Hebrides: MDCCLXXII. Part 2. London : Benjamin White, 1790 . iv +480 pp.

26. Boswell J. The Journal of a Tour to the Hebrides with Samuel Johnson, LL.D. New York : The Viking Press, $1936 . x v i i i+435$ pp.

27. Johnson S. A journey to the western islands of Scotland. London: Printed for W. Strahan; and T. Cadell in the Strand, 1775.384 p.

28. The Rev. Dr. John Walker Report on the Hebrides of 1764 and 1771 / ed. by M. MacKay. Edinburgh : John Donald Publishers, 2004 . vii+256 p.

29. Walker J. An Economical History of the Hebrides and Highlands of Scotland. Vol. I. Edinburgh : Printed at the University Press, 1808 . $x+389$ p.

30. Walker J. An Economical History of the Hebrides and Highlands of Scotland. Vol. II. Edinburgh : Printed at the University Press, 1808.416 p.

31. Note on an Account of the Number of People in Scotland in the Year 1755 by Alexander Webster // Journal of the Royal Statistical Society. 1922. Vol. 85, № 1. P. 105-106.

32. Youngson A.J. Alexander Webster and his "Account of the Number of People in Scotland in the Year 1755" // Population Studies. 1961. Vol. 15, № 2. P. 198-200.

33. The Statistical Account of Scotland. Vol. XX. Edinburgh : Printed and sold by William Creech, 1798. cxv+621 p.

34. Fussell G.E. Impressions of Sir John Sinclair, Bart., First President of the Board of Agriculture // Agricultural History. 1951. P. $162-169$.

35. Schumann U.M. The Hidden Roots of the Garden City Idea: From John Sinclair to John Claudius Loudon // Journal of Planning History. 2003. Vol. 2, № 4. P. 291-310.

36. Brunt L. The Advent of the Sample Survey in the Social Sciences // Journal of the Royal Statistical Society. Series D (The Statistician). 2001. Vol. 50, № 2. P. 179-189.

37. The Statistical Account of Scotland. Vol. XXI. Edinburgh : Printed and sold by William Creech, 1799. vii $+480+140$ p.

38. Steuart J. An inquiry into the Principles of Political Economy: being an essay on the Science of Domestic Policy in Free Nation. In which are particularly considered population, agriculture, trade, industry, money, coin, interest, circulation, banks, exchange, public credit, and taxes. Vol. I. London: Printed for A. Millar and T. Cadell, in the Strand, 1767. xv+652 p.

39. Mitcheson R. Agricultural Sir John: The Life of Sir John Sinclair of Ulbster. London : Geoffrey Bles, 1962. ix +291 pp.

40. Hilts V. Aliis Exterendum, or the origins of the Statistical Society of London// Isis. 1978. Vol. 69, № 1. P. $21-43$.

41. Kendall M.G. Studies in the History of Probability and Statistics. Where shall the history of statistics begin // Biometrika. 1960. Vol. 47 , № 3/4. P. 447-449.

42. Pearson K. The History of Statistics in the 17th and 18th Centuries, Against the Changing Background of Intellectual, Scientific and Religious Thought: Lectures by Karl Pearson given at University College London during the Academic Sessions 1921-1933 / E.S. Pearson (ed.). London : Griffin, 1978. xix+744 p.

43. Rosenbaum S. The growth of the Royal Statistical Society // Journal of Royal Statistical Association. Series A (General). 1984. Vol. 147, № 2: The 150th Anniversary of the Royal Statistical Society. P. 375-388.

44. The Statistical Account of Scotland. Vol. I. Edinburgh : Printed and sold by William Creech, 1791. xii +518 p.

45. The Statistical Account of Scotland. Vol. XVI. Edinburgh : Printed and sold by William Creech, 1795. vii+643 p.

46. The Statistical Account of Scotland. Vol. II. Edinburgh : Printed and sold by William Creech, 1791. xi+581 p.

47. The Statistical Account of Scotland. Vol. X. Edinburgh : Printed and sold by William Creech, 1794. viii $+637 \mathrm{p}$.

48. The Statistical Account of Scotland. Vol. III. Edinburgh : Printed and sold by William Creech, $1792 . x v i+612$ p.

49. The Statistical Account of Scotland. Vol. IV. Edinburgh : Printed and sold by William Creech, 1792 . vii +579 p.

50. The Statistical Account of Scotland. Vol. VIII. Edinburgh : Printed and sold by William Creech, 1793 . v +650 p.

51. The Statistical Account of Scotland. Vol. IX. Edinburgh : Printed and sold by William Creech, 1793 . vi+640 p.

52. The Statistical Account of Scotland. Vol. XII. Edinburgh : Printed and sold by William Creech, $1794 . \mathrm{v}+622 \mathrm{p}$.

53. The Statistical Account of Scotland. Vol. XIV. Edinburgh : Printed and sold by William Creech, 1795 . v +653 p.

54. The Statistical Account of Scotland. Vol. XV. Edinburgh : Printed and sold by William Creech, $1795 . \mathrm{v}+643 \mathrm{p}$.

55. Leeming F.A. Social accounting and the old statistical account // Scottish Geographical Magazine. 1963. Vol. 79, № 1. P. 34-48.

56. The Statistical Account of Scotland. Vol. V. Edinburgh : Printed and sold by William Creech, 1793. vi $+591 \mathrm{p}$.

57. The Statistical Account of Scotland. Vol. VII. Edinburgh : Printed and sold by William Creech, 1793 . vi +625 p.

58. The Statistical Account of Scotland. Vol. XI. Edinburgh : Printed and sold by William Creech, 1794. v+627 p.

59. The Statistical Account of Scotland. Vol. XIII. Edinburgh : Printed and sold by William Creech, 1794 . vi +664 p.

60. The Statistical Account of Scotland. Vol. XVII. Edinburgh : Printed and sold by William Creech, 1796. viii +650 p.

61. The Statistical Account of Scotland. Vol. VI. Edinburgh : Printed and sold by William Creech, 1793 . vii $+629 \mathrm{p}$.

62. The Statistical Account of Scotland. Vol. XVIII. Edinburgh : Printed and sold by William Creech, 1796. v+662 p.

63. The Statistical Account of Scotland. Vol. XIX. Edinburgh : Printed and sold by William Creech, 1797. vi $+631+14$ p.

Статья представлена научной редакцией «История» 10 ноября 2017 г.

\section{THE FIRST (OLD) STATISTICAL ACCOUNT OF SCOTLAND AS A DEMOGRAPHIC DATA SOURCE ABOUT THE POPULATION OF SCOTLAND OF THE END OF THE 18TH CENTURY}

Vestnik Tomskogo gosudarstvennogo universiteta - Tomsk State University Journal, 2018, 432, 159-169.

DOI: 10.17223/15617793/432/21

Arseniy L. Sinitsa, Lomonosov Moscow State University (Moscow, Russian Federation). E-mail: sinitsa@econ.msu.ru

Keywords: population of Scotland; first (old) statistical account of Scotland; John Sinclair; history of statistics; historical demography.

The article examines the population of Scotland at the end of the 18th century, which was a period of significant social transformation. Its main task is to investigate what demographic information can be obtained using data from the first (old) statistical account of Scotland and to provide some figures. The desire to conduct a survey like a statistical account throughout the country worried the minds of the Scots for a long time. Some attempts were made to do this. However, only increased attention to improvements in agriculture, the experience of A. Webster and other previous researchers and the philosophy of the Scottish Enlightenment were able to help J. Sinclair to conduct and publish the materials of the statistical account. The use of a uniform questionnaire for all parishes was 
among the unconditional successes of Sinclair. However, the priests could not provide the data in a suitable form for comparison on all issues. There are three reasons for this. First, to make a comprehensive answer the priests themselves did not always know what was going on in the parish, or they might not want to answer. Secondly, the answers were returning during a long period of time, but the situation in parishes changed quickly. Thirdly, there were many problems concerning the keeping of parish registers. Nevertheless, Sinclair was able to get a lot of important information. It was found that the population since 1755 increased by approximately 261 thousand people. This was a very good result for a small country taking into account the high emigration. For every 100 females, there were only 90 males, but at the youngest and oldest age the share of males was higher, because of the high emigration of males. About $41 \%$ of the population was younger than 20, and 39\% were in the range of 20 to 50 . More than 50 years had $17 \%$ of the population. According to the Rosset-Beaujeu-Garnier scale, it can be assumed that the population of Scotland was at the demographic youth or early stages of aging stage. The average family size was 4.6 persons, but they included single-person households. Taking into consideration the fact that in a marriage an average of 4-5 children were born, it can be assumed that the size of the family consisting of two or more people exceeded 5 persons. Data on migration in the statistical account are practically absent. Data on fertility, nuptiality and mortality are presented at a low level, because of the fact that in many parishes the registers were poorly kept. Basically they contain information about baptisms, announcements and burials, rather than births, marriages and deaths. Only sometimes the time of demographic events may be specified.

\section{REFERENCES}

1. Smout, T.C., Landsman, N.C. \& Devine, T.M. (1994) Scottish Emigration in the Early Modern Period. In: Canny, N. (ed.) Europeans on the Move: Studies on European Migration, 1500-1800. Oxford: Clarendon Press.

2. Dodgshon, R.A. (1992) Farming Practice in the Western Highlands and Islands before Crofting: A Study in Cultural Inertia or Opportunity Costs? Rural History. 3(2). pp. 173-189.

3. Zvidrin'sh, P.P. (1979) Naselenie Velikobritanii: razmeshchenie, sostav i vosproizvodstvo [The population of Great Britain: location, composition and reproduction]. Moscow: Statistika.

4. Laskova, N.V. (2014) "Demographic pressure" as background for the Scottish colonization of America in the XVII century. Istoricheskie, filosofskie, politicheskie i yuridicheskie nauki, kul'turologiya i iskusstvovedenie. Voprosy teorii i praktiki-Historical, Philosophical, Political and Law Sciences, Culturology and Study of Art. Issues of Theory and Practice. 6-1(44). pp. 112-115. (In Russian).

5. Laskova, N.V. (2016) The colonization of the Scottish outlying districts in the XVI and the first quarter of the XVII centuries. Vestnik Bryanskogo gosudarstvennogo universiteta - Bryansk State University Herald. 3 (29). pp. 43-46. (In Russian).

6. Laskova, N.V. (2011) Nesostoyavshiesya proekty shotlandskikh koloniy v Amerike Roberta Gordona iz Lokhinvara [The unsuccessful projects of Scottish colonies in America by Robert Gordon from Lochinvar]. Izvestiya vysshikh uchebnykh zavedeniy. Severo-Kavkazskiy region. Seriya: Obshchestvennye nauki. 1. pp. 70-74.

7. Koroleva, M.V. (2013) Trudy Dzhona Uokera o naselenii Gornoy Shotlandii i Gebridskikh ostrovov [Works of John Walker on the population of Mountainous Scotland and the Hebrides Islands]. Vestnik Moskovskogo universiteta. Seriya 6: Ekonomika - Moscow University Economics Bulletin. 2. pp. 54-61.

8. Urlanis, B.Ts. (1941) Rost naseleniya v Evrope (opyt ischisleniya) [Population growth in Europe (experience in calculus)]. Moscow: OGIZGospolitizdat.

9. Koroleva, M.V. \& Sinitsa, A.L. (2010) Gel'skoe naselenie Shotlandii - ot istokov k sovremennosti [The Gaelic population of Scotland - from the origin to the present]. In: Danilova, I.A. \& Kharaeva, O.A. (eds) Etnicheskaya demografiya [Ethnic demography]. Moscow: MAKS Press.

10. Flinn, M. (ed.) (1977) Scottish Population History from the Seventeenth Century to the 1930s. Cambridge: Cambridge University Press.

11. Moody, D. (1988) Scottish Family History. London: B.T. Batsford.

12. Kyd, J.G. (ed.) (1952) Scottish Population Statistics including Webstrer's Analysis of Population 1755. Edinburgh: Scottish History Society.

13. Smout, T.C. (1969) A history of Scottish People, 1560-1830. London: Collin.

14. Devine, T.M. (1999) The Scottish Nation 1700-2000. London; Allen Lane: The Penguin Press.

15. Bumsted, J.M. (1982) The People's Clearance. Highland Emigration to British North America. 1770-1815. Edinburgh: Edinburgh University Press, The University of Manitoba Press.

16. Withers, Ch.W.J. (1998) Urban Highlanders: Highland-Lowland Migration and Urban Gaelic Culture, 1700-1900. East Linton: Tuckwell Press.

17. Richards, E.A. (1982) History of the Highland Clearances. Vol. 1: Agrarian Transformation and the Evictions 1746-1886. London: Croom Helm.

18. Richards, E.A. (1985) History of the Highland Clearances. Vol. 2: Emigration, Protest, Reasons. London: Croom Helm.

19. Plackett, R.L. (1986) The Old Statistical Account. Journal of the Royal Statistical Society. Series A (General). 149(3). pp. $247-251$.

20. Pritchard, Ch. (1992) The Contributions of Four Scots to the Early Development of Statistics. The Mathematical Gazette. 76(475): The Use of the History of Mathematics in the Teaching of Mathematics. pp. 61-68.

21. Martin, M. (1703) A description of the Western Islands of Scotland: Containing a full account of their situation, extent, soils, product, harbours, bays, tides, anchoring places, and fisheries. The ancient and modern government, religion and customs of the inhabitants, particularly of their druids, heathen temples, monasteries, churches, chappels, antiquities, monuments, forts, caves, and other curiosities of art and nature. Of their admirable and expeditious way of curing most diseases by simples of their own product. A particular account of the second sight, or faculty of forseeing things to come, by way of vision, so common among them. A brief hint of methods to improve trade in that country, both by sea and land. With a new map of the whole, describing the harbours, anchoring places, and dangerous rocks, for the benefit of sailers. To which is added a brief description of the Isles of Orkney, and Schetland. London: Printed for Andrew Bell, at the Cross-Keys and Bible in Cornhill, near Stocks-Market.

22. Martin, M. (1884) A voyage to St. Kilda, the remotest of the Hebrides or Western Isles of Scotland: giving An Account of the very remarkable Inhabitants of that place, their Beauty and singular Chastity (Fornication and Adultery being unknown among them); their Genius for Poetry, Music, Dancing; their surprising Dexterity in climbing the rocks, and Walls of Houses; Diversion, Habit, Food, Language, Diseases and Methods of Cure; their extensive Charity; their Contempt of Gold and Silver, as below the Dignity of Human Nature; their Religious Ceremonies, Notion of Spirits and Visions, \&c. \&c.. London: D. Browne and L. Davis.

23. Monro, D. (1884) Description of the Western Isles of Scotland called Hybrides. With the Genealogies of the Chief Clans of the Isles by Sir Donald Monro High Dean of the Isles who travelled through most of them in the year 1549. Glasgow: Thomas D. Morison; London: Hamilton, Adams \& Co.

24. Pennant, Th. (1790) A tour in Scotland and voyage to the Hebrides: MDCCLXXII. Part 1. London: Benjamin White.

25. Pennant, Th. (1790) A tour in Scotland and voyage to the Hebrides: MDCCLXXII. Part 2. London: Benjamin White.

26. Boswell, J. (1936) The Journal of a Tour to the Hebrides with Samuel Johnson, LL.D. New York: The Viking Press.

27. Johnson, pp. (1775) A journey to the western islands of Scotland. London: Printed for W. Strahan; and T. Cadell in the Strand.

28. MacKay, M. (ed.) (2004) The Rev. Dr. John Walker Report on the Hebrides of 1764 and 1771. Edinburgh: John Donald Publishers.

29. Walker, J. (1808) An Economical History of the Hebrides and Highlands of Scotland. Vol. I. Edinburgh: Printed at the University Press.

30. Walker, J. (1808) An Economical History of the Hebrides and Highlands of Scotland. Vol. II. Edinburgh: Printed at the University Press.

31. Webster, A. (1922) Note on an Account of the Number of People in Scotland in the Year 1755 by Alexander Webster. Journal of the Royal Statistical Society. 85(1). pp. 105-106. 
32. Youngson, A.J. (1961) Alexander Webster and his "Account of the Number of People in Scotland in the Year 1755". Population Studies. 15(2). pp. 198-200.

33. Creech, W. (ed.) (1798) The Statistical Account of Scotland. Vol. XX. Edinburgh: Printed and sold by William Creech.

34. Fussell, G.E. (1951) Impressions of Sir John Sinclair, Bart., First President of the Board of Agriculture. Agricultural History. 25 (4). pp. 162-169.

35. Schumann, U.M. (2003) The Hidden Roots of the Garden City Idea: From John Sinclair to John Claudius Loudon. Journal of Planning History. 2(4). pp. 291-310.

36. Brunt, L. (2001) The Advent of the Sample Survey in the Social Sciences. Journal of the Royal Statistical Society. Series D (The Statistician). 50(2). pp. 179-189.

37. Creech, W. (ed.) (1799) The Statistical Account of Scotland. Vol. XXI. Edinburgh: Printed and sold by William Creech.

38. Steuart, J. (1767) An inquiry into the Principles of Political Economy: being an essay on the Science of Domestic Policy in Free Nation. In which are particularly considered population, agriculture, trade, industry, money, coin, interest, circulation, banks, exchange, public credit, and taxes. Vol. I. London: Printed for A. Millar and T. Cadell, in the Strand.

39. Mitcheson, R. (1962) Agricultural Sir John: The Life of Sir John Sinclair of Ulbster. London: Geoffrey Bles.

40. Hilts, V. (1978) Aliis Exterendum, or the origins of the Statistical Society of London. Isis. 69(1). pp. 21-43.

41. Kendall, M.G. (1960) Studies in the History of Probability and Statistics. Where shall the history of statistics begin. Biometrika. $47(3 / 4)$. pp. $447-449$.

42. Pearson, E.S. (ed.) (1978) The History of Statistics in the 17th and 18th Centuries, Against the Changing Background of Intellectual, Scientific and Religious Thought: Lectures by Karl Pearson given at University College London during the Academic Sessions 1921-1933. London: Griffin.

43. Rosenbaum, S. (1984) The growth of the Royal Statistical Society. Journal of Royal Statistical Association. Series A (General). 147(2): The 150th Anniversary of the Royal Statistical Society. pp. 375-388.

44. Creech, W. (ed.) (1791) The Statistical Account of Scotland. Vol. I. Edinburgh: Printed and sold by William Creech.

45. Creech, W. (ed.) (1795) The Statistical Account of Scotland. Vol. XVI. Edinburgh: Printed and sold by William Creech.

46. Creech, W. (ed.) (1791) The Statistical Account of Scotland. Vol. II. Edinburgh: Printed and sold by William Creech.

47. Creech, W. (ed.) (1794) The Statistical Account of Scotland. Vol. X. Edinburgh: Printed and sold by William Creech.

48. Creech, W. (ed.) (1792) The Statistical Account of Scotland. Vol. III. Edinburgh: Printed and sold by William Creech.

49. Creech, W. (ed.) (1792) The Statistical Account of Scotland. Vol. IV. Edinburgh: Printed and sold by William Creech.

50. Creech, W. (ed.) (1793) The Statistical Account of Scotland. Vol. VIII. Edinburgh: Printed and sold by William Creech.

51. Creech, W. (ed.) (1793) The Statistical Account of Scotland. Vol. IX. Edinburgh: Printed and sold by William Creech.

52. Creech, W. (ed.) (1794) The Statistical Account of Scotland. Vol. XII. Edinburgh: Printed and sold by William Creech.

53. Creech, W. (ed.) (1795) The Statistical Account of Scotland. Vol. XIV. Edinburgh: Printed and sold by William Creech.

54. Creech, W. (ed.) (1795) The Statistical Account of Scotland. Vol. XV. Edinburgh: Printed and sold by William Creech.

55. Leeming, F.A. (1963) Social accounting and the old statistical account. Scottish Geographical Magazine. 79(1). pp. 34-48.

56. Creech, W. (ed.) (1793) The Statistical Account of Scotland. Vol. V. Edinburgh: Printed and sold by William Creech.

57. Creech, W. (ed.) (1793) The Statistical Account of Scotland. Vol. VII. Edinburgh: Printed and sold by William Creech.

58. Creech, W. (ed.) (1794) The Statistical Account of Scotland. Vol. XI. Edinburgh: Printed and sold by William Creech.

59. Creech, W. (ed.) (1794) The Statistical Account of Scotland. Vol. XIII. Edinburgh: Printed and sold by William Creech.

60. Creech, W. (ed.) (1796) The Statistical Account of Scotland. Vol. XVII. Edinburgh: Printed and sold by William Creech.

61. Creech, W. (ed.) (1793) The Statistical Account of Scotland. Vol. VI. Edinburgh: Printed and sold by William Creech.

62. Creech, W. (ed.) (1796) The Statistical Account of Scotland. Vol. XVIII. Edinburgh: Printed and sold by William Creech.

63. Creech, W. (ed.) (1797) The Statistical Account of Scotland. Vol. XIX. Edinburgh: Printed and sold by William Creech.

Received: 10 November 2017 